Forthcoming in Foundations of Science

\title{
Identifying Difference, Engaging Dissent: What is at Stake in Democratizing Knowledge?
}

\author{
Loren King ${ }^{1}$, Brandon Morgan-Olsen ${ }^{2}$, and James Wong ${ }^{3}$
}

\begin{abstract}
Several prominent voices have called for a democratization of science through deliberative processes that include a diverse range of perspectives and values. We bring these scholars into conversation with extant research on democratic deliberation in political theory and the social sciences. In doing so, we identify systematic barriers to the effectiveness of inclusive deliberation in both scientific and political settings. We are particularly interested in what we call misidentified dissent, where deliberations are starkly framed at the outset in terms of dissenting positions without properly distinguishing the kinds of difference and disagreement motivating dissent.
\end{abstract}

The creation of cognitive democracy, of democratic science, is as much

a matter of conflict and hope as is the creation of political democracy.

Helen Longino, "Subjects, Power and Knowledge"

\section{Introduction}

Several recent voices in epistemology and the philosophy of science have called for a democratic turn in understanding how we seek and gain knowledge. Philip Kitcher calls for inclusion of all relevant parties in an "enlightened democracy" of knowledge production, where participants are carefully tutored to avoid "the danger of holding inquiry hostage to capricious and irrational desires" (Kitcher 2003, 124), but are nonetheless motivated by respect for other views

\footnotetext{
${ }^{1}$ Department of Political Science, Wilfrid Laurier University, Waterloo, Ontario, Canada

2 Department of Philosophy, Loyola University Chicago, Illinois, USA

${ }^{3}$ Department of Philosophy, Wilfrid Laurier University, Ontario, Canada
} 
(118-119). In this way, Kitcher hopes parties will transform their beliefs and preferences in light of compelling evidence and persuasive argument, while taking seriously a diversity of perspectives and interests. In a similar vein, Helen Longino calls for "critical discursive interactions," which allow the parties involved to determine what can be counted as knowledge (Longino 2002, 129ff).

Both these accounts of democratizing knowledge lean heavily on two intuitions, which Longino codifies into criteria for epistemically favourable exchanges. First, in spite of myriad differences and inequalities, we can reliably treat one another as competent reasoners and valid sources of knowledge claims. Longino calls this tempered equality. Second, mere voice is insufficient: we must treat other viewpoints and arguments with sufficient openness, allowing that our own beliefs and practices may ultimately be revised in light of our deliberative engagements. This is Longino's condition of uptake.

There is an important theme in contemporary political theory that parallels these arguments. For a certain sort of political philosopher and democratic theorist, deliberation is vital to democratic legitimacy. Philosophers and theorists have offered several distinct kinds of justification for enhanced publicity and greater deliberative inclusion. Some have hoped that inclusive deliberation will transform preferences and understandings in ways that ameliorate conflicts. Others cite desirable epistemic properties of inclusive deliberation. Still others link inclusive deliberation with a standard of legitimacy that is morally attractive independent of epistemic properties and transformative hopes. ${ }^{4}$

These philosophical efforts have been tempered, however, by a growing body of empirical work suggesting that the transformative and epistemic virtues of deliberation are at best difficult

\footnotetext{
4 For an elaboration of these rationales see King (2003). On epistemic features of deliberation and deliberative democracy, see, e.g., Peter (2009, ch. 3), and Estlund (2009, esp. 18ff).
} 
to achieve. There are lessons here for any efforts to democratize science in the ways Kitcher and Longino suggest: treating other persons and viewpoints as potentially authoritative turns out to be difficult in the moral and political sphere, so we may reasonably worry that the same will sometimes be true of claims to scientific knowledge, especially when those claims are cited in contentious policy debates.

In this paper, our aim is to bring the burgeoning work on democratizing science into fruitful dialogue with the now well-established philosophical and social-scientific branches of deliberative democratic theory. We engage in this synthetic analysis with an eye towards identifying systematic barriers to uptake that are of common interest to all in favor of inclusive deliberation, whether such deliberations are explicitly scientific in nature or otherwise.

We begin with the democratic turn in philosophy of science, focusing on Longino's account. We then draw elements of that account into conversation with some of the extant work on deliberative democracy, taking special note of how several empirical findings may suggest cautionary lessons for those who would be inclined to endorse something like Kitcher's or Longino's views. In doing so, we join others who have sought to connect these literatures in democratic theory and philosophy of science; we distinguish our efforts from related work inspired by Chantal Mouffe (Van Bouwel 2009), and discuss what we take to be the merits of our approach. Finally, we consider a type of uptake failure relevant for efforts to democratize science: misidentified dissent. This species of uptake failure occurs when deliberations are starkly framed at the outset in terms of dissenting views, without properly disambiguating between the kinds of difference and disagreement motivating dissent in the case at hand.

Disagreement can sometimes seem so deep and complex as to appear utterly intractable. Nonetheless, constructive argument can sometimes be sustained across even profound differences in interests and worldviews, and disagreement can sometimes be successfully 
framed against a background of evidence and argument that all parties accept as valid, even as they disagree deeply on matters of both policy and principle.

Our intention is to clarify the features of dissent of this kind, resting as it does-sometimes unnoticed, other times misidentified-in the conceptual and rhetorical spaces between principled agreement and an agonistic modus vivendi between conflicting interests and incommensurable worldviews. We hope that such clarification is helpful for both democratic theory and recent directions in social epistemology and the philosophy of science.

\section{Democratizing Science}

Recent work in philosophy of science has embarked on what Philip Kitcher calls the "road to democracy" (Kitcher 2002: 554). The path to democratization in knowledge is motivated by the rejection of the idea that the significance of truths can be determined objectively, independent of contexts, which Kitcher describes (rather idiosyncratically) as monism (555). While there are obvious and even profound differences in their approaches, both Kitcher and Helen Longino adopt a methodological pluralism in which what is significant is "relative to our cognitive capacities and our (changing) interests" (ibid). "Democraticism" follows from methodological pluralism; it represents a commitment to the inclusion of all relevant perspectives in the community of researchers-Longino's concern—or all parties in the community that are affected by what research projects are pursued-the focus of Kitcher's analysis (557). Longino's project shows how the justification of knowledge can proceed in a social way, while Kitcher's shows how the goals of science can respond to a variety of interests and perspectives.

\footnotetext{
5 The 'pluralism' we take from Kitcher and Longino is methodological, rather than substantive: for our purposes here we are agnostic on the further question of whether vigorous inclusion as a methodological commitment in science will result in a thoroughgoing pluralism of irreducible theoretical frameworks. Longino is certainly friendlier to that possibility than Kitcher, but even here we find support for our methodological emphasis and agnostic stance: see, e.g., Longino (2002, 140-142) and Kellert, Longino, and Waters (2006).
} 
The question that must be addressed for pluralists like Longino is how to arrive at knowledge from diverse contributions. Underlying Longino's answer to this question is her concept of critical discursive interactions which transform the subjective into the objective by ensuring that what is endorsed as knowledge has "survived criticisms from multiple points of view" (Longino 2002, 129). She proposes four conditions which would facilitate epistemically effective critical interactions.

1. Venues: There must be publicly recognized forums for the criticism of evidence, of methods, of assumptions and reasoning (ibid).

2. Uptake: There must be uptake of criticism. The community must not merely tolerate dissent, but its beliefs, theories and procedures must change over time in response to the critical discourse taking place (ibid).

3. Public Standards: There must be publicly recognized standards by reference to which theories, hypotheses and observational practices are evaluated and by appeal to which criticism is made relevant to the goal of the inquiring community. These standards are not a static set but may themselves be criticized and transformed in reference to other standards, goals, or values held temporarily constant (Longino 2002,130).

4. Tempered Equality: Communities must be characterized by equality of intellectual authority. ... This requirement implies both that the persuasive effect of reasoning and argument be secured by unforced assent to the substantive and logical principles used in them, rather than by properties, such as social or economic power, of those who are propounding them; and that every member of the community be regarded as capable of contributing to its constructive and critical dialogue (Longino 2002, 131-132).

These conditions specify how critical interactions between relevant points of view can facilitate effective epistemological critique and proceed to endorse particular claims put forward by the parties involved. Longino acknowledges that these conditions are ideal (Longino 1993, 113; Longino 2002, 134). Nonetheless they capture the intended 'spirit' of what is needed to make actual engagements with different points of view productive.

For example, the point of the public standards condition is to preclude the possibility that 
determining the results of one's or the group's inquiry can be achieved privately (ibid.). The point of the condition of tempered equality is to "ensure the exposure of hypotheses to the broadest range of criticism" from relevant perspectives (Longino 2002, 132). Longino points out that "as an epistemological criterion, [tempered equality] differs from equality as a moral or political criterion. The latter would require only that different perspectives have an equal chance of being included, whereas epistemic effectiveness requires that all (relevant) perspectives be included" (Longino 2002, n. 15, 131). ${ }^{6}$ So while the condition calls for inclusion, it does not follow that inclusiveness means that "every alternative view is equally deserving of attention" (Longino 1993, 118). Exactly what the criteria are for determining relevance is determined by the aims or goals of the inquiry, and cannot be detached from that context. Other complex issues prompted by the condition of tempered equality include questions about membership in the community of inquiry (Longino 2002, 133). It makes us ask "who constitutes the 'we' for any given group and what the criteria are for providing an answer" (ibid.). For Longino, then, the production of knowledge is both a rational pursuit and a political event. She tells us that in a power-stratified society, the inclusion of the less powerful is necessary because their views could serve as models for criticism of the received wisdom in the community. For her, "no segment of the community, whether powerful or powerless, can claim epistemic privilege" (ibid.).

Central to what makes criticism effective is the idea of uptake: that dissenting views are not merely tolerated, but rather all sides are committed to take seriously each other's positions

\footnotetext{
6 We accept Longino's characterization here for the sake of argument, but we doubt that the epistemic standard of equality is so easily disentangled from moral and political dimensions of equality. Such disentanglement is certainly difficult in practice, since failures of mutual respect grounded in legacies of socioeconomic inequality and unequal political standing can have epistemic consequences that Longino and others readily acknowledge. There is a comparable difficulty separating these dimensions in theory also: moral and political philosophers have, after all, spilt much ink on the question: 'equality of what?' Their varied answers-welfare, resources, capabilities, life chances, respect, standing as citizens-go far beyond the intuition that moral and political equality is exhausted by the condition that all have an equal chance at inclusion.
} 
(Longino 2002, 130). 'Uptake' also plays a key role in Kitcher's treatment of the discussion of values. Such discussions ought ideally to satisfy the conditions of mutual engagement, which is based on the recognition that "the perceived desires of those with whom one deliberates are given equal weight with one's own" (Kitcher 2011: 51). For Kitcher, participants in such conversations must be motivated by respect and the principle that others' claims are taken seriously.

How then does the kind of critical dialogue proposed by Longino and Kitcher deal with heterogeneity? Longino notes that in order to make constructive and potentially transformative ${ }^{7}$ dialogue epistemically effective, contributors must share some commonalities, such as referring terms, principles of inference, experimental practice, and the like (see also Kitcher 2011, 49-58). Contributors from within the same community of inquiry pose little problem because they presumably already share the same or much of the same frame of reference. Longino cites an example in ecology in which different experimental methods are employed. Ecosystems can be modeled on laboratory circumstances in which some variables are kept constant. For example, in an Oregon study of the result of the impact of ultraviolet (UV) radiation on amphibian populations, one laboratory examined the results of exposing frog eggs to UV radiation. They exposed one set of eggs to UV radiation, while another set was protected as control. However, another approach would be to study whether or not UV radiation has increased over time. These are two different methodologies: one focuses on the replicability and control of variables; the other on evaluating and predicting the effects of the change in UV radiation (Longino 2002, 177-78). In this example, the two approaches are driven by different questions which establish

\footnotetext{
${ }^{7}$ By singling out constructive dialogue, we have in mind the following distinction: the kinds of encounters both Longino and Kitcher have in mind may have desirable consequences even if they fail to move parties from their favoured positions-if, for instance, deliberation clarifies the sources of disagreement, or introduces new sources of evidence and directions of inquiry. So even if dialogue doesn't change peoples' beliefs or attitudes, it may still be constructive.
} 
different standards of evaluation, but both approaches are following shared rules. Since the research answers different sets of questions, it would be inappropriate to foreclose on one or the other approach. Critical interaction between the two might yet lead to an understanding of the limits of such methodologies and may yet moderate the results from such research (Longino 2002, 197).

However, efforts to identify shared features are made more difficult for contributions from different communities of inquiry owing to the vagaries of "cross-cultural communication and translation" as in, for example, cases between western and non-western medicine (Longino $2002, n .20,130)$. Assuming such translation succeeds in identifying commonalities for the sake of argument, contributors are able to evaluate each other's results by shared standards.

In addition, there may be cases in which translation isn't the difficulty, but that there are obstacles barring successful engagement between participants in the dialogue. Longino cites two such examples: wrongheaded content (Longino 2002, 157-158) and wrongheaded rules (Longino 2002, 159-162). To illustrate, let's consider the wrongheaded content example. ${ }^{8}$ The example deals with the creationist's claim that her belief is as warranted epistemically as any other scientific claim (157). Longino argues that the creationist's account does not meet the norms of effective criticism which require openness to criticism from perspectives that can connect to "some standards of the creationist community to count as knowledge"-in this case, the origins of the physical universe. The commitment of the creationist community to salvation as the principle underlying their inquiry only insulate their cognitive goals from those of other communities of inquirers. The claims of the creationist scientists, then, would not count as scientific knowledge because of their commitment not to participate in open effective criticism. ${ }^{9}$

\footnotetext{
${ }^{8}$ An example of wrongheaded rule would be one in which observational practices in an inquiry are restricted to reading tea leaves.

${ }^{9}$ In our judgement, the creationist community typically forfeits on the status of their claims, owing to their failure to take up the views of other approaches in the ongoing critical discourse. Sometimes this failure of
} 
In this example, there is little possibility of uptake for the other parties to learn from another point of view.

Pluralists like Longino and Kitcher do not regard the content of knowledge as fixed.

Questions are open within the proposed structure of a critical transformative dialogue: results are always only provisionally endorsed, however stable and enduring the endorsement may be. ${ }^{10}$ It is always possible that future results or future interactions with other perspectives may prompt reassessment about claims and also about which communities are to be included. Knowledge is dynamic, not static (Longino 2002, 135). Matters are quite different outside the structure for critical interaction proposed by Longino, such as when there is no uptake of alternative points of view and issues are black-boxed. As illustrated in the debate between science and creationist science, such black-boxing results in closed structures between which debate is not possible.

\section{Deliberation and Systematic Uptake Failure}

As we've seen, Longino and Kitcher both emphasize the importance of uptake for legitimate, democratic knowledge-productive practices. And it should be clear that characterizing uptake will involve careful attention paid to both the proposals forwarded into deliberation and the social

uptake is subtle, in the form of selective uptake for rhetorical purposes, while still grounding alleged scientific efforts in unchallengeable core beliefs that are immune from evidentiary or theoretical challenge. We cannot argue the point here, but our sense is that recent efforts to engage this community (by, for example, Steven Fuller 2008 and Thomas Nagel 2008) fail to take seriously this deeply problematic feature of allegedly scientific challenges to evolutionary theory by intelligent design advocates. Neither Fuller nor Nagel ask the obvious question: why don't intelligent design researchers actually try to study conjectured intelligent design, using the methods available and widely used in the social and historical sciences? (Economists and historians routinely ask, for example, whether or not some consequence of a given legislated policy or military engagement was the result of design, or merely accidental).

10 In an earlier work, Longino notes that her proposed pluralist account faces a dilemma: "If objectivity requires pluralism in the community, then scientific knowledge becomes elusive, but if consensus is pursued, it will be at the cost of silencing critical oppositional positions" (Longino 1993, 114). The strategy she adopts to avoid the dilemma is to "detach scientific knowledge from consensus, if consensus means agreement of the entire scientific community regarding the truth or acceptability of a given theory" (ibid., italics added). 
relations between the relevant deliberators. Indeed, in her campaign to jettison the traditional rational-social dichotomy, Longino implies that these two objects of study must be regarded together. To view deliberative contributions as if they could be analyzed in an abstract space of propositional content would be to ignore the irreducibly social nature of human justificatory practices. To concentrate exclusively on social phenomena like power relations and identity formation would be to myopically discount mechanisms of evidence, logic, and inference. One must instead treat "agents or subjects of knowledge as located in particular and complex interrelationships ... [which] can be understood as a rich pool of varied resources, constraints, and incentives to help close the gap left by logic" (Longino 2002, 128).

The literatures on democratic deliberation and deliberative democracy are helpful in two ways here: they provide a complementary philosophical account of the conditions under which morally attractive deliberation proceeds, but they also provide empirical findings that help to concretize the difficulties involved in following up on Longino's right-headed but ultimately abstract prescription. ${ }^{11}$

First, then, in political-philosophical treatments of deliberation, the roughly equivalent conditions to Longino's tempered equality and uptake are (i) civility and mutual respect, and (ii)

\footnotetext{
${ }^{11}$ We note here the difference, well-explained by Simone Chambers (2009), between democratic deliberation and deliberative democracy. We do not sustain the distinction in our discussion, however, since the underlying theoretical work we draw on is common to both strands of theory. That said, some of the empirical findings on deliberation that we cite are precisely what motivates the move from deliberative democracy to democratic deliberation that concerns Chambers: she draws the distinction to emphasize, analyse, and redress a move away from concerns about the mass public character of democracy in deliberative theory. In recognition of the difficulties of reconciling deliberative aspirations with well-known problems of spatial and organizational scale in democratic politics, advocates of deliberation have begun to focus far more attention on the question of how to democratize various tractable forms of group deliberation, and worried correspondingly less about how a democracy en toto might be made more deliberative. In general we think it fair to say that the democratic turn in philosophy of science is concerned with democratic deliberation-rendering deliberative processes democratic-and not deliberative democracy. (For instance, one might wonder about the status of scientific knowledge production within a theory of deliberative democracy, but that is not our concern here, nor of the philosophers we are engaging. However, it is certainly a question worth asking.)
} 
sincerity and seriousness with respect to deliberative engagement. While rules of civility needn't be stringent, at the very least we must let others present their testimony, offer facts, make observations; and in doing so we treat them as, to adopt and extend John Rawls's elegant characterization, "self-authenticating sources of valid claims" (Rawls 2005, 72). Further, we listen to them, and make our own cases, with an openness that allows we might be persuaded to change our own views after our engagements. In this sense, then, our engagements are sincere, and our openness to other views evinces a seriousness of resolve: we commit ourselves to the possibility of transformed expectations and understandings. We do not merely listen and talk strategically, seeking our own pursuits and feigning respectful engagement only insofar as this better serves our aims. ${ }^{12}$

Second, in its empirical mode, deliberative theory calls attention to the social dynamics and institutional influences, jointly epistemic and political in nature, which can affect our collective judgements about effective uptake. Let us refer to these varied intervening factors-formal institutions, cognitive heuristics and biases, cultural norms-as mediating structures, working between pre-deliberative inputs and post-deliberative judgements. Implementing the democratization of knowledge necessitates taking stock of the mediating structures already in place-especially those with pernicious tendencies-alongside sober analysis of the viability of moving forward with measures designed to manipulate, dismantle, or replace these structures.

\footnotetext{
12 Invoking Rousseau, we allow that our deliberations together may lead us to discover and freely affirm a general will that is not simply the will of all, or of some. In the literature on deliberative democracy the openness condition is most often discussed in the same breath as toleration, although the condition of openness is typically framed as civility and mutual respect: "In deliberative settings, citizens manifest their equality with each other not only by refraining from interference with their acts of expression; they also do so by sustaining the conditions for communication. How do they do this? They do so reflexively, in their communication with each other in public deliberation and in their attitudes towards others as participants in a public process ... Toleration in this sense is at minimum discursive openness" (Bohman 2003, 763). Scanlon (1996) sees that toleration commits us to the perhaps uncomfortable possibility of a changed social environment.
} 


\section{Debating Science, Debating Politics}

There are, to be sure, important distinctions between the scientific and political cases, specifically with respect to the kinds of mediating structures that are especially relevant and problematic. Indeed, in the moral and political case it is arguable that Longino's two other conditions - of authoritative venues, on the one hand, and widely accepted standards of relevant evidence and rules of inference, on the other-simply do not obtain.

First, in the cacophonous public spheres of contemporary democracies, there are some historically prominent venues (venerable media outlets; courts and legislatures) that are widely viewed as authoritative information providers and interpreters. These claims to authority are, however, often challenged by both scholarly and partisan voices, and a great many other venues (particularly in cyberspace) vie for comparable respect.

Second, on the matter of shared rules of evidence and inference, there are clear incentives for powerful actors to distort information and promulgate dubious claims, in ways that are perhaps harder to challenge than in the case of scientific knowledge claims. The incentives for citizens to remain rationally ignorant on a range of public matters is often noted, and may in part reflect awareness, by citizens, of the difficulties in finding consensus in the moral and political realm regarding what even counts as reasonable evidence and convincing argument on deeply divisive matters of policy and principle. ${ }^{13}$

\section{Motivating Dissent: Varieties of Disagreement}

With these caveats in mind, we know turn to the kinds of differences and disagreements that motivate dissent. Our aim here is to elaborate further on how insights from the political and

\footnotetext{
13 These distortions and perverse incentives are central, for instance, to Pincione and Teson (2006) on the persistence of what they call "discourse failure" and their associated critique of deliberative democratic proposals.
} 
moral spheres may be useful for efforts to democratize science. One particularly relevant complementarity between political and scientific contexts is the fact that these contexts, when democratized, have in common certain kinds of conflict, and being clear on these is, we contend, crucial to keeping track of uptake. In this light, consider the following kinds of disagreement that can arise in democracies.

In some cases, there may be a genuine fact of the matter concerning a public question: for example, whether a policy will reduce crime or increase employment. Here, disagreements might be at least in part rooted in simple errors of fact or reasoning or, of course, deliberate distortions of facts and arguments. Call these factual disputes. Disagreements in factual disputes are rooted either in error or dishonesty.

In other cases, disagreements may simply reflect conflicting tastes, sentiments, needs_-in a word, interests. Fair division problems with scarce resources often have this character, for instance: there may only be sufficient materials available to satisfy some, but not all desires, or even brute needs, if scarcity is stark. Evidence and argument may well clarify the nature and extent of such conflicts, and even reveal their causes, but is unlikely to resolve them. Call this interest agonism. Interests are not immutable, of course, but they often are settled features of who we are, and so the best we might hope for when settled interests conflict is that, by understanding the nature and extent of those differences, we might also debate what values are to guide us in negotiating compromises and finding strategies of mutual accommodation.

In still other cases, disputes do not stem simply from conflicting interests, nor errors in fact or reasoning, but are the result of profound differences in worldviews and resultant disagreements over what counts as relevant and reliable evidence, what constitute persuasive arguments, and what values ought to inform and restrain law and policy. Call this worldview agonism. Suppose, for example, that your policy proposal to limit stem cell research-based 
solely on religious convictions about God's plan for every potential human life-carries the day, and my only response is "well that's just unscientific!" Here we have an instance of worldview agonism: I offer only my assertion of scientific standards of inference and argument against your assertion of religious convictions, but I find myself facing a majority who share your worldview.

The two species of agonism are distinct, but are likely to be related: deep differences in worldviews are likely to result, over time, in distinct communities of tastes and interests. They are both, however, distinct from factual disputes, where we agree on the terms of debate, and where some fact of the matter is relatively uncontentious, but as yet undetermined. In factual disputes, we simply need good evidence and argument to forge a legitimate consensus around the truth of the matter. In disputes grounded in brute differences in needs, tastes, and desires, there is the possibility of bargaining and compromise, even morally principled accommodation, but these disputes are defined by either objective needs or settled preferences that are not part of the calculus of deliberative engagement. Rather, they are taken as given.

So too with some kinds of settled commitments to particular worldviews, and the standards of evidence and argument that go along with those comprehensive spiritual and philosophical doctrines. ${ }^{14}$ If I, and my fellow believers, simply refuse to accept your favoured standards of what count as persuasive arguments and reliable evidence (because, perhaps, you refuse to accept the existence of god, or the inerrancy of our favoured interpretation of sacred texts), then we can easily find ourselves in disputes of much the same character as that associated with interest

\footnotetext{
${ }^{14}$ Our meaning is consonant with Rawls, who gives us the idea of a comprehensive doctrine as including "conceptions of what is of value in human life, as well as ideals of personal virtue and character that are to inform much of our nonpolitical conduct" $(2005,175)$. As is clear from this passage, however, Rawls is primarily concerned with distinguishing political conceptions of justice and legitimacy from those derived from more comprehensive religious-spiritual and moral-philosophical systems of thought. Our usage is more capacious, including especially core ontological and epistemic commitments that condition knowledge claims and define valid inferences. An example: some religious-spiritual worldviews commit adherents to accepting private subjective mental states as convincing evidence, that in turn justifies faith in the existing of supernatural realms and beings. These are the kinds of deep and settled commitments that are of particular interest to us here.
} 
agonism: in both cases, the sources of disagreement are not in dispute, but are also largely immune to agreement. In the case of interest agonism, dissent is rooted in brute conflict. In the case of worldview agonism, dissent arises insofar as meaningful argument about particular scientific hypotheses or political proposals cannot even get off the ground: the parties do not accept compatible rules of inference and evidence..$^{15}$

We can, however, imagine disputes that are not brute conflicts of tastes and interests, on the one hand, but also are not transparently the result of deep disagreements about ontological and epistemic fundamentals, on the other. The kinds of disagreement we have in mind proceed from a space of underlying agreement—or at least, sufficient convergence—on relevant evidence and acceptable rules of inference. These disputes may involve, for example, thorny interpretive debates, disagreements about the weighing and/or prioritization of values, adjudication of apparent value conflicts, or questions about the contexts of application for shared principles.

Here, critically, the motivating disagreement seems to parties to be, at least in principle, rationally resolvable, insofar as parties roughly agree on what an acceptable claim would look like. Still, these disagreements, while in principle resolvable, do not simply dissolve under straightforward corrections of fact and reasoning; neither are they mere precipitates of more fundamental incommensurability with respect to either tastes and interests, or foundational assumptions and commitments. To put the point roughly, but simply: parties in these cases more or less accept the (logical and evidentiary) terms of debate, they are sufficiently informed, and they argue sincerely and plausibly, but they nonetheless disagree over what conclusions follow.

When dissent reflects disagreements of this sort, parties cannot be dismissed as simply having different needs and tastes; nor is their disagreement an instance of a deeper clash of

\footnotetext{
${ }^{15}$ Recall here the importance, for Longino, of widely shared and reasonably settled public standards in the generation of valid knowledge through inclusive critical interactions.
} 
antagonistic worldviews. What is tantalizing about such dissent is the prospect for rational resolution in spite of profound disagreement. Parties to such disputes sincerely want to find an answer that would satisfy all or most parties; but they cannot agree with the prevailing interpretations and arguments that seem ready to carry the day.

To be clear, the varieties of conflict we distinguish are idealized types; disagreements are not always easily characterized as one of these ideal types in practice. Still, clarifying the kinds of disputes that motivate dissent invites us to consider the spaces between these conceptual poles, and how what seems to be one kind of disagreement might in fact resolve itself into something else entirely. In actual political and scientific controversy, what seems at first to be unresolvable dissent may turn out to be mere strategic posturing, with some party adopting the language of deep religious convictions or scientific scepticism to further more mundane material or ideological interests. Or, perhaps, a persistent dissenting voice, apparently baying against the winds of reason and evidence, will ultimately reveal that the prevailing consensus, seemingly so certain, in fact relies on a subtle evidentiary mistake, or an unsustainable interpretation of some core concept. Think here, for example, of how the concept of a "calorie" transformed from an assumed entity, an ontological status, to a unit of measurement in a very different model of heat (Hacking 1983, 86-7; Psillos 1996). ${ }^{16}$

For many moral and political issues, the evidence is complex and uncertain; and our interpretations of that evidence, as well as the weight we grant to particular facts, are inevitably shaped by our values, interests, and experiences. What seems obviously true to us and many others may admit of reasonable challenge, and persistent dissent may eventually expose subtle biases and errors in our views. While the problems wrestled with in most fields of science seem

\footnotetext{
${ }^{16}$ We simply note this as a plausible example of how dissent can eventually challenge status quo understandings in science; for our purposes here we take no sides in the dispute over convergent realism where this example is often invoked, e.g. Laudan (1981) and Lewis (2001).
} 
to admit of far more (and more stable) intersubjective certainty than moral and political disputes, it still shouldn't surprise us of these same "burdens of judgement," ${ }^{17}$ which motivate respect for reasonable dissent in the moral-political realm, may have some relevance in the realm of science, especially when considering the kinds of dissent we see, for instance, against complex model-dependent knowledge claims in evolutionary theory or climate sciences.

\section{Agonism, Transformation, Consensus}

We have suggested that some kinds of disagreement allow for dissent that cannot be easily dismissed as either fruitless or disingenuous, relying as it does on sincere and informed parties agreeing upon rules of inference and evidence, yet nonetheless leading to unsettled conclusions. Still, we might think that this kind of disagreement-leading to what we will here call unsettled dissent-is unlikely to remain unsettled for long. After all, if we can find some measure of agreement on basic rules of inference and admission of evidence relevant to a given dispute, then how likely is it that substantive disagreement could persist? Wouldn't such disputes eventually be shown to originate in either brute differences in tastes and interests, subtle mistakes of fact and reasoning, or in deeper foundational disagreements on the very terms of debate? In short, this critic argues that unsettled dissent is simply an unstable, perhaps illusory point between interest and worldview agonism, on the one hand, and relatively uncontentious

\footnotetext{
17 We draw here on what John Rawls $(2001,33-37)$ calls the burdens of judgement: on the most profound and important questions of morality and politics, evidence is complex and uncertain, and even when we can provisionally agree on what evidence is relevant, reliable, and how we ought to reason about those facts, factual questions almost never settle the matter of how to weigh competing considerations, and how best to interpret available evidence. Thus, while we may be firmly convinced of the truth of our views, we allow that other intelligent, informed, sincere interlocutors may reasonably disagree on these kinds of questions. These burdens are central to Rawls's idea of reasonable disagreement, (see esp. 2005, 36ff and 134ff), but we do not claim that such disagreement is synonymous with the kind of potentially fruitful dissent that especially interests us here. We simply cite acceptance of these burdens of judgement as an obvious way that sincere and informed disagreement could persist on complex and contentious issues.
} 
knowledge and truth claims (factual disputes), on the other.

This kind of critic points to a real worry in moral and political philosophy: what if, ultimately, democratic politics is most often rooted in interest and worldview agonism, rather than the kinds of questions that admit of a legitimate consensus on facts and values? Different cultural, religious, and philosophical traditions—-the critic contends—simply approach the big questions in life with incommensurable beliefs about how the world works, what values should guide our lives together, what counts as persuasive argument, what evidence is relevant to those assumptions and arguments, and how we should interpret and weigh the significance of alleged facts. These traditions result in ways of life with distinctive tastes and interests, and these will inevitably conflict with those of other traditions, other worldviews. The best we might hope for here, as Chantal Mouffe $(1993 ; 1999)$ suggests, is that disputing parties come to see themselves as adversaries rather than enemies:

an adversary is a legitimate enemy, an enemy with whom we have in common a shared adhesion to the ethico-political principles of democracy. But our disagreement concerning their meaning and implementation is not one that could be resolved through deliberation and rational discussion, hence the antagonistic element in the relation $(1999,755)$.

We agree with Mouffe that such transformations are surely desirable in the face of disputes rooted in interest and worldview agonism. We also agree with Jeroen Van Bouwel (2009) that Longino's approach can be allied with Mouffe's insofar as both evince clear scepticism that deliberation ought to aim at authoritative consensus. Longino, as Van Bouwel rightly notes, is far more concerned with inclusive procedures than with privileging consensus as the desired outcome of deliberation. This, he suggests, leads Longino to a model of "agonistic engagement" (Van Bouwel 2009, 129) that is quite friendly to Mouffe's view.

Still, the critic we are considering here seems to assume that there is no stable point between interest and worldview agonism, on the one hand, and uncontentious facts and 
inferences that should motivate consensus, on the other. On the critic's view, either disputes are amenable to evidence and argument (in which case dissent reflects ignorance, ineptitude, or dishonesty) or they are not; if not, then inclusive deliberation solves nothing substantive, at least not without first convincing everyone to hold compatible tastes, cultivate common interests, and share a common worldview.

However tempting, we resist this assumption, for two reasons:

First, we contend that unsettled dissent, as we have defined it, can be durable and is worth taking seriously. To be clear, we applaud philosophical and theoretical efforts to scrutinize consensus as a moral or epistemic ideal, and as a practical aim, especially as it relates to scientific knowledge-claims and their public consequences (e.g., Miller 2013). We do not dispute that Mouffe and other agonists do indeed have plausible targets for their criticisms. Some advocates of deliberation are overly sanguine about the possibility and desirability of consensus: Jürgen Habermas comes to mind, and Van Bouwel $(2009,127)$ makes a good case for putting Kitcher in this category. We contend, however, that deliberation in the moral and political realm is not so tightly bound to consensus as might at first seem to be the case.

This last point seems to us to deserve particular emphasis: inclusive deliberation need not issue in consensus to be useful or otherwise morally attractive. Deliberation may instead serve to clarify the various dimensions of complex disputes, showing us where and how, precisely, we disagree (e.g. Miller 1992), and again, even suggesting novel lines of inquiry that may have been obscured by pre-deliberative disagreement. The rich literature on democratic deliberation and deliberative democracy suggest, then, that deliberation need not be motivated by substantive consensus, but may instead have other epistemic and legitimating functions, including but not limited to the kind of modest transformation in mutual appraisals that Mouffe suggests.

Second, while Mouffe's agonism certainly allows for the possibility of productive interactions 
under a "conflictual consensus," $" 18$ that possibility comes at a cost. Not only does she deny the possibility of "rational procedures" ever "overcoming" dissenting interpretations of core political values $(2005,228)$, she holds that productive interactions through agonistic channels require 'conversion' rather than 'persuasion'. For Mouffe, "to come to accept the position of the adversary is to undergo a radical change in political identity, it has more of a quality of a conversion than of rational persuasion (in the same way as Thomas Kuhn has argued that Hey adherence to a new scientific paradigm is a type of conversion)" $(1999,755)$. She is, then, sceptical of the possibility of intersubjective convergence on truth or likelihood as motivating personal transformations. We, however, want to allow such convergence as a possible (although certainly not necessary) consequence of inclusive deliberation. ${ }^{19}$ Like Longino, we maintain an agnostic position that does not prejudge the results of deliberation, although with Mouffe and other hopeful agonists, we suspect that a certain kind of transformation in our attitudes towards others will be a desirable outcome of appropriately structured deliberative encounters with others. In addition to those modest transformative aims of inclusive deliberation, our focus is on the deliberative frameworks that can further encourage favourable epistemic results, such as clarifying the dimensions of disputes and even issuing in provisional consensus. We contend that Longino's rejection of the rational/social dichotomy and her articulation of the social norms for "effective critical interactions" highlights the rational elements of persuasion in a way that is friendlier to our view than to Mouffe's (Longino 2002, 128-135). We hasten to add,

\footnotetext{
${ }^{18}$ For Mouffe, this is a consensus on "the 'ethico-political' principles of the liberal democratic regime, that is, liberty and equality for all," but where "there should always exist the possibility of serious dissent about their interpretation" $(2005,228)$. We thank an anonymous reviewer for pushing us to clarify this contrast with Mouffe's position.

19 More pointedly, we suspect that personal conversions-however difficult and unlikely-will sometimes have rational or at least reasonable grounds. Or, if these transformations really are as mysterious as Mouffe seems to suggest, we suspect that those conversions are at least occasionally the result of exposure to different (but rational) assumptions, evidence, interpretations, and arguments.
} 
though, that we do not presume that all things epistemic are strictly rational. Not at all, for that would mean upholding the problematic rational/social dichotomy against which Longino rightly argued.

\section{Cautionary Lessons}

Having suggested that deliberative approaches gleaned from political theory may be more promising than some critics have intimated, we turn to more pessimistic lessons for approaches such as Kitcher's and Longino's-lessons drawn from empirical work on political deliberation. To this end, consider a troubling set of mediating structures that recent empirical work on deliberation has highlighted.

A longstanding body of work in social psychology finds that groups are easily polarized by deliberation, with like-minded participants conforming to more extreme positions than they might otherwise have endorsed (see Sunstein 2002; and 2007, ch. 3). More recently, in a careful study of experimental and survey data, Dianne Mutz (2006) has found a clear tradeoff between participation and deliberation in the face of disagreement: the kinds of people who participate actively in politics do not tend to engage in much deliberation with others, certainly not outside their favoured beliefs and opinions.

Worse, when citizens are exposed to a diversity of beliefs, viewpoints, and arguments, they tend to participate less in politics (Mutz 2006). Similarly, Simon Jackman and Paul Sniderman (2006) have found modest but suggestive evidence that, in everyday political argument, deliberation—understood as engagement with opposing evidence and argument—does not seem to have much effect on subsequent beliefs.

There are ways around these pernicious psychological tendencies, and most prominent in democratic theory has been the pioneering work of James Fishkin, whose statistically 
representative deliberative polls bring together a wide range of citizens to discuss specific public issues under careful moderation, copious information, and relevant expert testimony. Several researchers, working between normative political theory and empirical social sciences (e.g. Fung 2006; Goodin and Dryzek 2006; Tansey \& Burgess 2006; Guston 2007; MacKenzie and Doherty 2011; Niemeyer 2011; see also Chambers 2003; and Thompson 2008), continue to explore the precise institutional architectures favorable to successful group deliberations in a variety of settings. Yet there are obvious moral concerns that these sorts of solutions (emphasizing as they do the importance of moderation, and controlling information and access to expertise) may complicate the very hopes-for more broadly inclusive democratization of knowledge access, evaluation, and production —-that motivate the turn to democratic deliberation in the first place.

A prevalent and particularly pernicious mediating structure-the effects of which careful moderation seeks to ameliorate-consists of ingrained stereotypes and associated biases inherent in public political culture, which leave particular groups at a deliberative disadvantage. Think here of the systematic barriers to comprehension that Miranda Fricker describes as forms of "epistemic injustice" (2007). Fricker introduces the notion of "testimonial injustice" to describe the disvaluing of a speaker's credibility that can occur when the speaker is the victim of prejudice or the object of malicious stereotyping (2007, chp. 1). Fricker also speaks of "hermeneutical injustice", where widespread cultural misinterpretation causes subaltern groups difficulty in conceptualizing certain of their social experiences and contributing to the collective understanding of these experiences (2007, ch. 7). As a result, these marginalized individuals face difficulties in making political claims that stem from these experiences (Morgan-Olsen 2010). An important critical theme in the debates over deliberative democracy drives home much the same point, showing how apparently benign norms of civility in discourse can in fact exclude 
particular gestures and speaking styles historically linked to oppressed and socioeconomically marginalized ethnic, racial, and cultural groups (e.g., Saunders 1997; Young 2001; Bohman 2003). These injustices are particularly significant because they present barriers to uptake that are integrated into the epistemic norms by which we all operate, meaning that those affected "are confronted with a double bind: not only are their voices not heard, but the structures through which this happens are hidden from view" (Martineau 2012, 172).

The general lesson here is that to maximize uptake, it is not sufficient to track bare facts like inclusion of individuals or minority voices in critical discursive interaction. One must also analyze the set-up conditions of the deliberative process in order to make sense of whether such inclusion is effective, and to increase the chances of excavating mediating structures that are serving to hinder unfairly the uptake of particular deliberative contributions. To consider a specific instantiation of this general phenomenon, let us turn towards an analysis of how deliberations can be framed so as to systematically misidentify dissent by conflating unsettled dissent with worldview agonism.

\section{Misidentified and Manufactured Dissent}

It should be clear at this point that those in favor of democratizing science and deliberative theorists alike tend to worry about deep failures of understanding and insular value judgements that will lead to the recalcitrant disagreement of black-boxed deliberation. In short, they worry about the possibility of worldview agonism. ${ }^{20}$ These worries generally arise in reaction to prominent, contentious public disputes, as in Longino's reaction to the claims of creationist science. In such cases, as we've also seen with Longino, often a call is made for "translation" of

20 There is, of course, considerable debate among theorists about whether such worries are warranted or ill-advised. Charles Taylor, for example, has an optimistic take on this question, insisting that the driving problem in democratic communication is not incommensurability, but the fact that we face "the jackals and vultures of partial and (we hope) surmountable noncommunication' $(2002,291)$. 
concepts or evaluative frameworks in order to identify commonalities and resolve dissent.

But such disputes do not spring into being fully-formed. There is a pre-deliberative stage where views are canvassed, relevant evidence is identified, and positions are identified as dissenting or assenting with respect to the question at hand. Uptake failure can occur at this stage, as mediating structures interfere with the criteria invoked to classify disagreements as conflictual or recalcitrant. We are especially interested in these antecedent hindrances to the uptake that Longino and Kitcher seek. In this respect, Longino's and Kitcher's proposals can benefit, we suggest, from attention paid to the sources of dissent, especially the degree to which worldview agonism really is at work in some particular disputes.

Here, then, we move from our earlier discussion of broader questions-about how perspectives and worldviews can generate the disagreements that motivate and frame dissent-to specific disputes over, for instance, particular policies in the political realm, or specific hypotheses or research proposals in the scientific realm (and, of course, cases where these intersect, when specific research findings have moral and political valence).

To begin to get at the question of how unsettled dissent can get quickly classified as unresolvable agonism, we can point towards exemplary cases in contemporary debates about multiculturalism and religious accommodation. Consider, for example, Carolin Emcke's line of questioning about "the so-called 'headscarves affair' in France (and its analogues elsewhere)", in which she argues:

To say that this controversy exemplifies the tendency for the simple fact of pluralism to generate "normative or practical contradictions" seems question-begging: how, exactly, does what a Muslim girl wears on her head in school come to represent a threat to the survival of French secularism? Does this signification somehow inhere in the practice as such, prior to and independently of its encounter and interaction with its "external" context? $(2000,500)$

Emcke here calls attention to the process by which a pre-theoretically benign cultural difference became strongly representative of a divisive political conflict. To be sure, the choice of the 
headscarf as a locus of conflict makes sense in that it serves as a symbol of identification for certain Muslims (and as a symbol of gender oppression to other participants in the debate). But the fact that this in itself trivial cultural difference was so quickly ratcheted up to an instance of deep conflict raises questions about the initial framing of the debate and the characterization of the opposing parties.

Consider also the Quebec National Assembly's motion to ban the wearing of the kirpan, a symbolic dagger worn by members of the Sikh religion, in the provincial legislature. ${ }^{21}$ The motion was carried ostensibly on grounds of security, as the provincial legislature, reasonably, has a policy against the wearing of weapons. Since the kirpan is a dagger, and thus a weapon, the National Assembly concluded that it should not be allowed. However, Sikhs argue that the kirpan is a religious symbol akin to the wearing of a cross or a kippah, and that it is not a weapon. What is important here, though, is that no Sikh came forward to disagree with the professed motivation for the policy. No one argued that the importance of a religious symbol trumps concerns of security; no one argued that a loaded rifle should get through the door, whether it has religious significance to its owner or not. Yet Quebec championed this case to demonstrate the importance of maintaining its staunch secularism, and of resisting the tolerance of religious constituencies that is embraced by the other provinces of Canada. Again, we have an issue of a particular, trivial religious and cultural difference being quickly regarded as an instance of deep conflict.

It is easy to see the possibility of malicious political spin taking place in these examples. And,

\footnotetext{
${ }^{21}$ The National Assembly unanimously passed the motion in early 2011, inciting a national debate (see, e.g., "Kirpan Banned at Quebec National Assembly" http://www.cbc.ca/news/canada/montreal/story/2011/02/09/pq-kirpan-measure.html (accessed 10.1.2011), and "Kirpan Ban Puts Canada on Brink of Multiculturalism Debate No One Wants" http://www.theglobeandmail.com/news/politics/ottawa-notebook/kirpan-ban-puts-canada-on-brink-of-multicult uralism-debate-no-one-wants/article1903372/ (accessed 10.1.2011).
} 
indeed, similar phenomena of manufactured controversy take place in disputes surrounding the public understanding of science, such as the debate over teaching Intelligent Design in American schools. ${ }^{22}$ We will revisit this point below, but overt manipulation is not all that is going on when dissent is misidentified or mis-characterized. At least some of what went awry in the framing of the affair du foulard, for example, can be traced to public misunderstandings (and outright ambiguities) about the cultural meaning of the headscarf. This is just to reiterate that, oftentimes, mediating structures can complicate the collective epistemic task of setting up a democratic debate, to the detriment of some deliberators' attempts to get uptake. Such worries lead to the question of what criteria are used to characterize the degree to which dissent is likely to be constructive. More specifically, one ought to wonder on what grounds we distinguish deep value conflicts from, for example, more immediate conflicts of interest. While such criteria can certainly be maliciously manipulated, they can also be problematized without specifically malicious intention.

Discourse about dissent can be misleading because it often occurs on a level that does not illuminate the substance of a debate between two parties in disagreement; the discourse generally focuses on a particular political policy or proposition, meaning that the political camps involved will be neatly separated into pro- or against- camps with little regard for the reasons individuals consider decisive in joining one of these camps. But the discourse can also be misled by policy proposals that are not transparent about their underlying motivations; sometimes it is far from clear why a particular deliberative proposal is being enacted, and thus those who dissent from the proposal because they disagree with one possible motivation for it might seem to be in sharper conflict with others than they really are.

With this in mind, and against the backdrop of our earlier discussion of the varieties of

\footnotetext{
${ }^{22}$ For insight into how controversy can be manufactured in scientific debates, see, e.g., Ceccarelli (2011).
} 
disagreement that can motivate dissent, we offer a taxonomy that establishes a more fine-grained conceptualization of forms of dissent, aimed at the level of policies and proposals, thus offering a potential tool for minimizing mis-categorization and maximizing effective uptake. For these purposes, let us assume that every proposed political policy has a single overriding motivation that underlies it. This limits our taxonomy to four options:

1. Full Assent: when one assents to a policy and agrees with its underlying motivation.

2. Attenuated Assent: when one assents to a policy, but does not agree with its underlying motivation. (In other words, one has a distinct motivation for assenting to the policy that overrides the presented motivation, which leads to something of an overlapping consensus.)

3. Full Dissent: when one disapproves of both the policy and its underlying motivation.

4. Attenuated Dissent: when one does not necessarily disagree with the underlying motivation of the policy, but disapproves of the policy on some other grounds.

We want to call particular attention to the case of attenuated dissent, where groups express dissatisfaction with a deliberative proposal but their motivations for dissatisfaction are often poorly understood or mis-categorized. This is what is happening most often, we contend, when consequential mistakes are made in misidentifying dissent.

One might characterize the headscarf and kirpan cases as instances of attenuated dissent, but there are more striking illustrative examples, such as the ongoing negotiations between indigenous groups and the Canadian government over land claims. As Paul Nadasdy argues—referencing, in particular, Kluane First Nation (KFN) land claims in the Canadian Subarctic- the deliberations about aboriginal title that have taken place in Canadian courts are framed around a notion of property that alienates many First Nations groups from the outset (Nadasdy 2002) ${ }^{23}$ The Western notion of property qua individualistic private property does not map well onto traditional KFN concepts of land use and management. Thus, ".. the land claim

${ }^{23}$ Thanks to Burke Hendrix for pointing us towards this specific example. 
process-because it forces aboriginal people to think and speak in the language of property —-tends to undermine the very beliefs and practices that a land claim agreement is meant to preserve" (ibid., 247).

This case is striking not simply because it involves the translation of concepts for the purposes of deliberation, as Longino cautions might be necessary at times ${ }^{24}$ nor because we can speculate about the existence of malicious intervention in the debate's history. ${ }^{25}$ It is striking because, despite appearances, the difference between Aboriginal and Western conceptualizations of land use is not what is ultimately at issue. What is at issue is who gets to govern what tracts of land-an issue fully intelligible within each framework of conceptualization and potentially resolvable without anything resembling a full resolution of the conceptual disconnect between frameworks. However, as it stands, the deliberation has been framed so that it is very difficult to express clearly the First Nations perspective-even leaving aside the massive power imbalances at play. Thus, the differences between the parties seem more relevant than they might be in another light (one, for example, that highlights common interests in sustainable resource use, environmental protections, and uncontaminated air, water, soil, etc.).

To illustrate, imagine a court proposing to grant a KFN leader ownership of a huge swath of the Yukon, with the understanding that the KFN group will engage in collaborative stewardship of the territory. As a whole, the Kluane Nation would likely not disagree with the spirit of the proposal, but they are still placed in an awkward position of attenuated dissent due to the fact that they do not endorse the notions of ownership built into the foundations of the court's operating principles.

24 "... to even engage in the process of negotiating a land claim agreement, First Nation people must translate their complex reciprocal relationship with the land into the equally complex but very different language of 'property'" (Nadasdy 2002, 248).

${ }^{25}$ Nancy Williams argues that, historically, the legal notion of "property rights" were defined explicitly in contradistinction to aboriginal conceptualizations, in order to stack the debate in favor of the courts (1986, ch. 8). 
These cases call attention to ways in which the line between unsettled dissent and worldview agonism can be obscured in the public political debate of modern democracies. The enterprise of science has by no means been historically free of political maneuvering, explicitly manufactured controversy, or the sway of public opinion. It is not unreasonable to suppose that the democratization of scientific knowledge production will more directly expose science to pathologies of public political discourse, like this tendency to conflate dissent and difference. So the question to ask of proponents of democratization is whether they have built sufficient safeguards into their accounts to militate against such destructive tendencies.

For instance, to revisit an example cited earlier in passing, consider how challenges to a morally and politically charged consensus in climate science, surrounding the reality and likely impacts of anthropogenic warming, are often framed. Here, dissenting voices are often assumed (and often revealed) to be partisan interests masquerading as reasonable challenges to interpretations of complex models and associated evidence. Yet the models so central to climate science are indeed extraordinarily complex, sensitive, and admit of reasonable debates over model specification and testing. Here, as in the moral and political case (and perhaps in some measure because this too is importantly an instance of interpreting and weighing moral values, and setting priorities, e.g. Broome 2012), we must distinguish carefully where dissent is based on the unsettled character of evidence and argument, and where it instead reflects dishonesty in the service of particular interests.

Here too, however, we should also see the space for attenuated dissent: accepting the scientific claims (about human involvement in climate change) that motivate particular policy recommendations (rapid cuts to emissions) and future research projects (for instance, in pollution abatement and alternative fuels), but disputing those policies and research priorities. Bjorn Lomborg's critical interventions into the climate debate (e.g. Lomborg 2004) are an obvious 
illustration of this: his constructive point, whatever one thinks of it, ${ }^{26}$ was not to dispute the relevant climate science, but to highlight the human development priorities that seemed likely to be undercut by aggressive policy interventions and applied research aimed at dramatic emission reductions.

Longino and Kitcher are obviously both aware of the overt mechanisms of power that can skew deliberative processes, which can manifest themselves in, for example, strategies of privatization, disenfranchisement, and political "spin". Our aim here is simply to clarify how some of these real-world deliberative complexities play out in the moral and political spheres, and especially in those areas of scientific research with clear moral and political valence, all with an eye to aiding those who would draw on deliberative practices and procedures for democratizing science. We have drawn here on the moral and political spheres to elaborate a taxonomy of public dissent. Our hope is that this exercise may be of use in thinking through the practical implementation of more democratic ways of doing science.

\section{Concluding Remarks}

Debates surrounding deliberative democracy continue to reveal subtle and pernicious mediating structures which must be guarded against in order for deliberation to be successful, epistemologically speaking. In putting the literature on democratizing science into conversation with political theory and social science concerned with public deliberation, we hope to have raised awareness of sources of uptake failure that may be critical to the success of efforts to democratize scientific knowledge and practice. We are especially concerned that scientific debates not be left vulnerable to framing effects such as those we have canvassed in the preceding discussions.

\footnotetext{
${ }^{26}$ For an example of harsh criticism, see Friel (2010).
} 
The phenomena of misidentified and manufactured dissent should be of special interest to Philip Kitcher and Helen Longino, because these phenomena themselves can influence the empirical landscape used to judge the long-term plausibility of democratizing knowledge. An unrepresentative illusion of preponderant dissent can lead us to characterize our polity solely in terms of persistent disagreement and an unmanageable gridlock of conflicting values. This characterization, in turn, can be used as evidence to justify more insular scientific practices and policy considerations, and to reject principles that encourage collaboration and deliberation across lines of difference, like those championed by proponents of democratization. Moreover, there are forces of political expediency that will seek to encourage such characterizations. We take it that this point is relatively uncontroversial, but let us briefly adduce two considerations in its favor.

First of all, presenting one's view as if it is in sharp conflict with another's is a useful strategy for getting one's voice heard. With limited time and patience for arbitrating subtle disputes, public political discourse tends to operate on a point/counter-point model of debate between two conflicting sides of an issue. The more easily distinguished these different sides are, the more effectively the debate can be framed. Hence, it often behooves one to push a political agenda that is in stark contrast to an existing view rather than offering a conciliatory yet revisionary view. Moreover, if there is a received view on a particular issue, one is almost guaranteed to gain a political presence by disagreeing with it strongly.

Secondly, an extended period of unproductive engagement favors those who have entrenched power. As long as there is hope for mutual advantage and concordance, there is a prima facie reason for deliberation to continue. In contrast, as gridlock continues and tension mounts, the point of decision approaches more quickly; if we are convinced that "never the twain shall meet," we will be motivated to take a vote and move on. As this process moves more 
quickly, the opportunities for the marginalized to represent themselves dwindle, and the likelihood that they will be stonewalled increases. Thus, claims of gridlock provide an air of legitimacy to attempts made by those in power to push their agendas through complaint without making any substantial compromises.

In sum, it is both politically and theoretically important for theorists and philosophers of science to recognize and attend to mediating structures that may work to misidentify dissent, thus warping the way public debates over scientific knowledge claims-and especially policy implications—are framed. These structures ultimately provide cover for the disingenuous manufacture of dissent and create barriers to effective uptake.

\section{References}

Bohman, James. 2003. "Public Deliberation, Democracy and the Limits of Pluralism," Philosophy and Social Criticism 29,1: 85-105.

Broome, John. 2012. Climate Matters: Ethics in a Warming World. NY: Norton.

Ceccarelli, Leah. 2011. "Manufactured Scientific Controversy: Science, Rhetoric, and Public Debate." Rhetoric \& Public Affairs: 195-228.

Chambers, Simone. 2003. "Deliberative Democratic Theory." Annual Review of Political Science 6: 307-326.

----. 2009. "Rhetoric and the Public Sphere: has Deliberative Democracy Abandoned Mass Democracy?" Political Theory 37, 3 (June): 323-350.

Cohen, Joshua. 1996. "Procedure and Substance in Deliberative Democracy." In Democracy and Difference: Contesting the Boundaries of the Political, ed. Seyla Benhabib. Princeton: Princeton University Press.

Dryzek, John S. 2000. Deliberative Democracy and Beyond: Liberals, Critics, Contestations. New York: Oxford University Press.

Emcke, Carolin. 2000. "Between Choice and Coercion: Identities, Injuries and Different Forms of 
Recognition. Constellations 7(4): 483-495.

Estlund, David M. 2009. Democratic Authority: a Philosophical Framework. Princeton: Princeton University Press.

Fishkin, James S. and Robert C. Luskin. 2005. "Experimenting with a Democratic Ideal: Deliberative Polling and Public Opinion." Acta Politica 40, 3 (September): 284-298.

Fricker, Miranda. 2007. Epistemic Injustice: Power and the Ethics of Knowing (Oxford; New York: Oxford University Press).

Friel, Howard. 2010. The Lomborg Deception: Setting the Record Straight about Global Warming. New Haven: Yale University Press.

Fuller, Steve. 2008. Dissent over Descent: Intelligent Design's Challenge to Darwinism. London: Icon.

Fung, Archon. 2006. Empowered Participation: Reinventing Urban Democracy (Princeton: Princeton University Press).

Goodin, Robert E., and John Dryzek. 2006. "Deliberative Impacts: the Macro-Political Uptake of Mini-Publics." Politics and Society 34, 2 (June): 219-244.

Guston, D.H. 2007. "The Center for Nanotechnology in Society and the Prospects for Anticipatory Governance," pp. 377-92 in N. Cameron and M. Ellen Mitchell, eds., Nanoscale: Issues and Perspectives for the Nano Century (New York: John Wiley and Sons).

Habermas, Jürgen. 1996. Between Facts and Norms: Contributions to a Discourse Theory of Law and Democracy (Cambridge, Mass.: MIT Press).

Hacking, lan. 1983. Representing and Intervening: Introductory Topics in the Philosophy of Natural Science. Cambridge: Cambridge University Press.

Jackman, Simon and Paul M. Sniderman. 2006. "The Limits of Deliberative Discussion: a Model of Everyday Political Arguments.” Journal of Politics 68, 2 (May): 272-283.

Kellert, S., H. Longino, and C. K. Waters. 2006. "Introduction: The Pluralist Stance" in Scientific Pluralism, edited by Stephen Kellert, Helen Longino, and C. Kenneth Waters (Minneapolis; University of Minnesota Press): vii-xxix.

King, Loren A. 2003. "Deliberation, Legitimacy, and Multilateral Democracy." Governance 16, 1 (January): 23-50.

Kitcher, Philip. 2002. "The Third Way: Reflections on Helen Longino's The Fate of Knowledge," Philosophy of Science, 69 (no. 4): 549-559.

----- 2003. Science, Truth and Democracy (Oxford; New York: Oxford University Press). 
----- 2011. Science in a Democratic Society (Amherst, New York,:Prometheus Books).

Laudan, Larry. 1981. "A Confutation of Convergent Realism." Philosophy of Science 48, 1 (March): 19-49.

Lewis, Peter J. 2001. "Why the Pessimistic Induction is a Fallacy." Synthese 129, 3 (December): 371-380.

Lomborg, Bjorn. 2004. The Skeptical Environmentalist: Measuring the Real State of the World. Cambridge: Cambridge University Press.

Longino, Helen. 1993. "Subjects, Power and Knowledge." In Feminist Epistemologies, edited by Linda Alcoff and Elizabeth Potter (New York: Routledge): 101-120.

---- 2002. The Fate of Knowledge (Princeton: Princeton University Press).

MacKenzie, Michael Kenneth and Kieran O'Doherty. 2011. "Deliberating Future Issues:

Minipublics and Salmon Genomics." Journal of Public Deliberation 7, 1: 1-27

Martineau, Wendy. 2012. "Misrecognition and Cross-Cultural Understanding: Shaping the Space for a "Fusion of Horizons." Ethnicities 12 (April): 161-177.

Miller, Boaz. 2013. "When is Consensus Knowledge Based? Distinguishing Shared Knowledge from Mere Agreement." Synthese, forthcoming.

Miller, David. 1992. Deliberative Democracy and Social Choice. Political Studies 40 (special issue):54-67.

Morgan-Olsen, Brandon. 2010. "Conceptual Exclusion and Public Reason." Philosophy of the Social Sciences 40(2): 213-243.

Mouffe, Chantal. 1993. The Return of the Political (London: Verso).

----- 1999. "Deliberative Democracy or Agonistic Pluralism?” Social Research 66: 745-758.

----. 2005. "The Limits of John Rawls' Pluralism." Politics, Philosophy, and Economics 4, 2 (June): 221-231.

Mutz, Diana Carole. 2006. Hearing the Other Side: Deliberative Versus Participatory Democracy (Cambridge University Press).

Nadasy, Paul. 2002. "'Property' and Aboriginal Land Claims in the Canadian Subarctic: Some Theoretical Considerations." American Anthropologist 104 (March): 247-261.

Nagel, Thomas. 2008. "Public Education and Intelligent Design." Philosophy and Public Affairs 36, 2 (Spring): 187-205.

Niemeyer, Simon. 2011. The Emancipatory Effect of Deliberation: Empirical Lessons from 
Mini-Publics." Politics and Society 39, 1 (March):103-140.

Peter, Fabienne. 2009. Democratic Legitimacy. London: Routledge.

Pincione, Guido and Téson, Fernando R. 2006. Rational Choice and Democratic Deliberation: A Theory of Discourse Failure (Cambridge University Press).

Psillos, Stathis. 1996. "Scientific Realism and the 'Pessimistic Induction'." Philosophy of Science 63 (Proceedings): S306-S314.

Rawls, John. 2001. Justice as Fairness: a Restatement. Erin Kelly, ed. Cambridge, MA: Belknap.

-----.2005. Political Liberalism. Expanded Edition. New York: Columbia University Press.

Saunders, Lynn M. 1997. "Against Deliberation." Political Theory 25, 3 (June): 347-376.

Scanlon, T. M. 1996. "The Difficulty of Tolerance" In Toleration: An Elusive Virtue, ed., David Heyd (Princeton: Princeton University Press):226-239

Sunstein, Cass R. 2002."The Law of Group Polarization." Journal of Political Philosophy 10, 2 (June): 175-195.

----. 2007. Republic.com 2.0 (Princeton: Princeton University Press).

Tansey, J and Burgess, M.M. 2006. "Complexity of Public Interest in Ethical Analysis of Genomics: Ethical Reflections on Salmon Genomics/Aquaculture," Journal of Integrative Assessment 6, (no. 2): 37-57.

Thompson, Dennis F. 2008. "Deliberative Democratic Theory and Empirical Political Science." Annual Review of Political Science 11 (June): 497-520.

Van Bouwel, Jeroen. 2009. "The Problem With(out) Consensus: The Scientific Consensus, Deliberative Democracy, and Agonistic Pluralism," pp. 121-142 in Jeroen Van Bouwel, ed, The Social Sciences and Democracy (London: Palgrave MacMillan).

Williams, Nancy. 1986. The Yolngu and Their Land: A System of Land Tenure and the Fight for Its Recognition. Stanford: Stanford University Press.

Young, Iris. 2001. Inclusion and Democracy. Oxford: Oxford University Press. 